九州大学学術情報リポジトリ

Kyushu University Institutional Repository

\title{
Study on Wind Shear Acting on the Water Surface of Closed Water Bodies
}

Lap, Bui Quoc

Graduate School of Bioresource and Bioenvironmental Sciences, Kyushu University

Tuan, Nguyen Van

Faculty of Agriculture, Kyushu University

Mori, Ken

Faculty of Agriculture, Kyushu University

Hirai, Yasumaru

Faculty of Agriculture, Kyushu University

https://doi.org/10.5109/9289

出版情報：九州大学大学院農学研究院紀要. 52 (1)，pp.99-105，2007-02-28. Faculty of Agriculture， Kyushu University

バージョン :

権利関係 : 


\title{
Study on Wind Shear Acting on the Water Surface of Closed Water Bodies
}

\author{
Bui Quoc LAP ${ }^{1}$, Nguyen Van TUAN, Ken MORI* and Yasumaru HIRAI
}

\author{
Laboratory of Bioproduction and Environment Information Sciences, Division of Bioproduction and \\ Environment Information Sciences, Department of Bioproduction and Environment Science, \\ Faculty of Agriculture, Kyushu University, Fukuoka 812-8581, Japan \\ (Received November 8, 2006 and accepted December 1, 2006)
}

\begin{abstract}
To simulate water quality in closed water bodies, it is necessary to simulate their circulation first because the circulation is closely related to the distribution of water quality variables in the closed water bodies. In simulation of the circulation in the closed water bodies, the study on wind stress acting on their water surface is prerequisite because in the closed water bodies, where the exchange with external waters is usually small, wind becomes the main factor help them circulate. Therefore, the main objective of this research is to investigate how the wind acts on the water surface and how the wind friction velocity spatially varies on the water surface of the closed water bodies through conducting indoor experiments. The experimental apparatus includes a rectangular tank filled with water modeling on a closed water body, a wind generating machine and a wind speed measuring sensor (Kanomax Japan Inc.). The measurements of wind velocity profiles above the water surface were conducted with the variety of average wind speed (U) under different percentages of aquatic plant coverage on the water surface. The results of this research indicate that when the effect of waves is negligible, the spatial variations of the wind friction velocity and the water surface velocity are relatively homogeneous along the free water surface. In addition, the water surface velocity is about $3 \%$ of the wind speed on average. These results are very useful for simulating the wind-induced flow in closed water bodies.
\end{abstract}

\section{INTRODUCTION}

Closed water bodies such as lakes and reservoirs are major surface water sources for life. They play an important part in many aspects of life including drinking water supply, power generation, navigation, agricultural irrigation, etc. However, due to the poor exchange with external waters, many water quality problems such as thermal stratification, lack of oxygen in the bottom layer, eutrophication, etc., usually occur, which may degrade their water quality. Therefore, the closed water bodies are still the subject of great environmental concern. In the closed water bodies, one of the important physical processes, which greatly affects the water quality is their circulation because it closely related to the distribution of water quality variables.

Circulation in the closed water bodies is primarily caused by wind shear acting on the water surface, affected partly by density gradients. Winds blowing over the closed water bodies' surface tend to mix the surface waters and transfer heat down through the water column (Chapra, 1997) by causing the wind-induced flow in the closed water bodies (Lap and Mori, 2006). Depending on the season, heat transfer tends to either raise or lower the temperature in the top layers of lakes or reservoirs as a consequence of factors, including solar radiation, air temperature, relative humidity, wind speed, causing the different distribution of water tem-

${ }^{1}$ Laboratory of Bioproduction and Environment Information Sciences, Division of Bioproduction and Environment Information Sciences, Department of Bioproduction and Bioenvironment Sciences, Graduate School of Bioresource and Bioenvironmental Sciences, Kyushu University

* Corresponding author (Email: moriken@bpes.kyushu-u.ac.jp) perature along the depth of lakes or reservoirs, which is called the thermal stratification. Due to the thermal stratification, in summer, waters in the top layers are usually lighter than those in the bottom layers, which can be resistant to the mixing caused by wind in closed water bodies. Moreover, in summer, the excessive growth of floating aquatic plants such as algal or water hyacinth usually occurs. Floating aquatic plants can greatly affect the circulation by reducing wind force acting on the water surface through narrowing the free water surface, and by influencing the thermal disturbance in the closed water bodies through affecting the heat exchange at the water surface covered by them.

Therefore, studying the wind acting on the water surface in the closed water bodies is great of significance in studying the wind-induced flow and their water quality. From that perspective, this research has been done. The research has concentrated on investigating how the wind acts on the water surface and how the wind friction velocity spatially varies on the water surface of the closed water bodies. Experimental methods and results of the research have been shown in detail below.

\section{MATERIALS AND METHODS}

\section{Laboratory apparatus}

The experiments were conducted with laboratory apparatus which includes a rectangular tank filled with water modeling on a closed water body as shown in Fig. 1 , a wind generating machine and a wind speed measuring sensor (Kanomax Japan Inc.). The rectangular tank has a length of $6 \mathrm{~m}, 0.3 \mathrm{~m}$ in width, and the height of $0.7 \mathrm{~m}$. The tank is filled with water up to $0.4 \mathrm{~m}$ in height. One end of the tank is connected to the wind generating 
machine whose wind speed can be adjusted.

The wind speed measuring sensor is shown in Fig. 2. When measuring, it is placed on the tank as shown in Fig. 3.

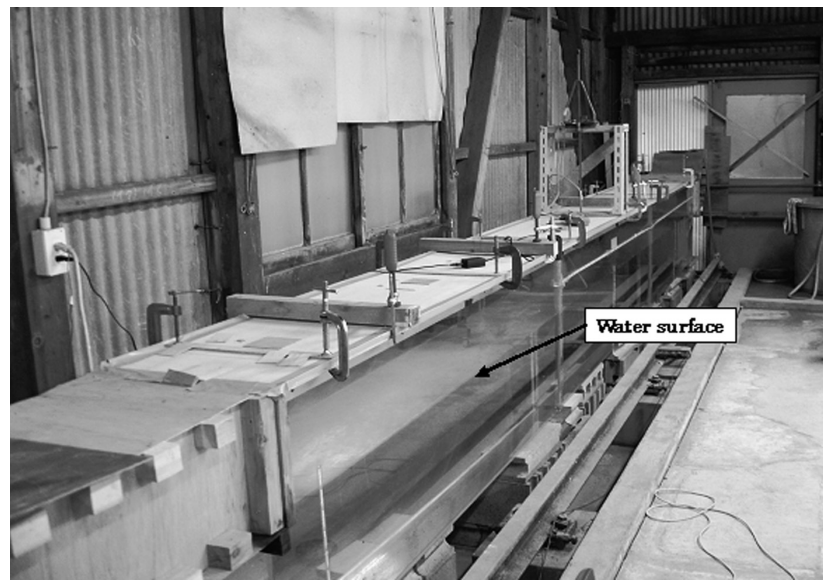

Fig. 1. Rectangular tank filled with water modeling on a closed water body.

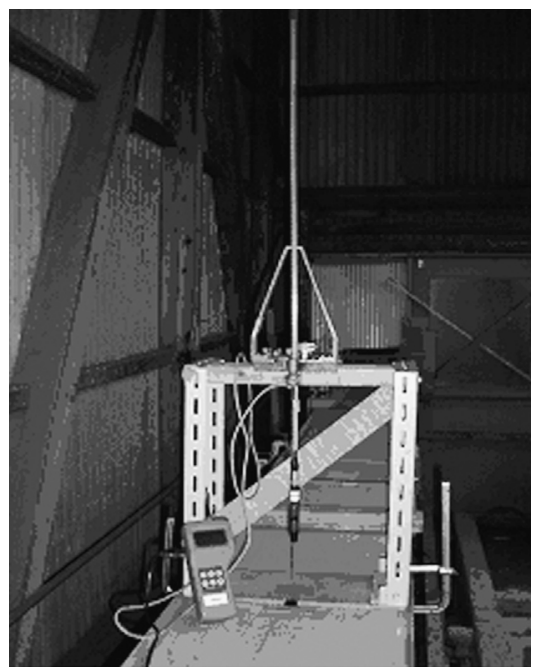

Fig. 2. Wind speed measuring sensor.

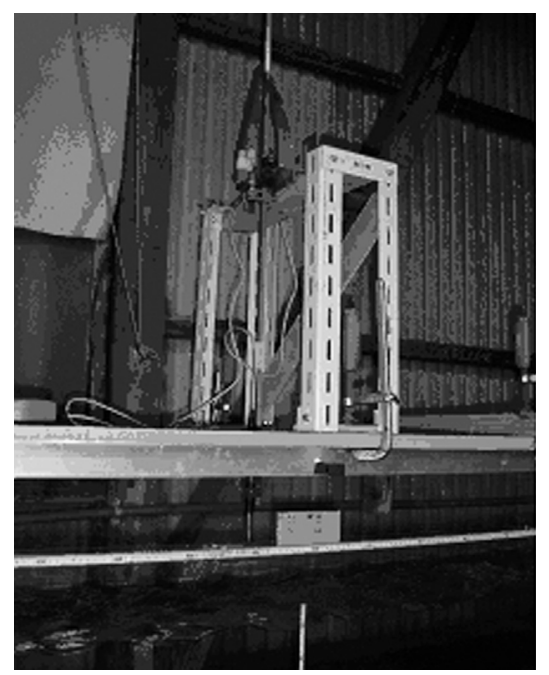

Fig. 3. Measurement of wind speed above water surface.

\section{Measurement method}

Velocity profiles above the water surface in the rectangular tank are measured at each cross-section with intervals of $1 \mathrm{~m}$ along the tank. Vertical intervals for wind speed measurement at each cross-section range from $0.5 \mathrm{~cm}$ to $1.0 \mathrm{~cm}$ for $15 \mathrm{~cm}$ in height above the water surface.

The measurement was done in five cases including $0 \%, 10 \%, 20 \%, 35 \%$, and $50 \%$ of aquatic plant coverage on the water surface of the tank as outlined in Fig. 4 below.

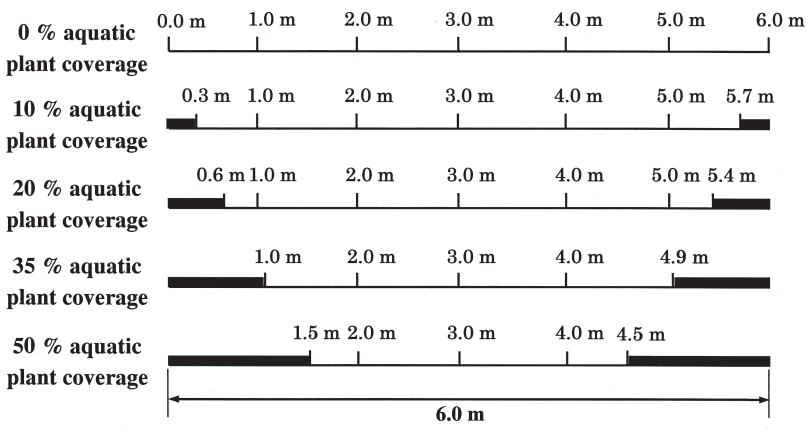

Fig. 4. Cases of wind speed measurement.

Average wind speed (U) blowing on the water surface is set up at $2 \mathrm{~m} / \mathrm{s}, 4 \mathrm{~m} / \mathrm{s}, 6 \mathrm{~m} / \mathrm{s}$ and $8 \mathrm{~m} / \mathrm{s}$ for each case.

\section{Calculation of wind friction velocity and the water surface velocity}

Wind friction velocity is calculated as follows:

$$
\frac{U(z)}{u_{*_{a}}}=\frac{1}{\kappa} \ln \frac{z}{z_{o}}
$$

where $U(z)$ is wind velocity at the height of $z, u_{*_{a}}$ is wind friction velocity, $\mathrm{k}$ is Karman coefficient (0.4), $z_{o}$ is roughness length.

From (1) we have:

$$
\frac{U\left(z_{1}\right)-U\left(z_{2}\right)}{u_{*_{a}}}=\frac{1}{\kappa} \ln \frac{z_{1}}{z_{2}}
$$

Formula (2) is used to calculate the wind friction velocity in this research.

The wind friction velocity is relevant to water surface velocity in closed water bodies by the following equation:

$$
u_{s}=u_{*_{a}} \sqrt{\frac{\rho_{a}}{C_{D} \rho_{w}}}
$$

where $\rho_{a}$ is air density, $\rho_{w}$ is water density, $C_{\mathrm{D}}$ is drag coefficient $\left(1.0 \times 10^{-3}\right)$ (Fischer et al., 1979), $u_{s}$ is water surface velocity. 


\section{RESULTS AND DISCUSSION}

The measurement results of vertical wind velocity profiles and natural logarithm profiles of wind velocity
$15 \mathrm{~cm}$ above the water surface along the tank are shown in Fig. 5-Fig. 9 below.

From the measurement results of wind velocity above the water surface shown in Fig. 5-Fig. 9 above,
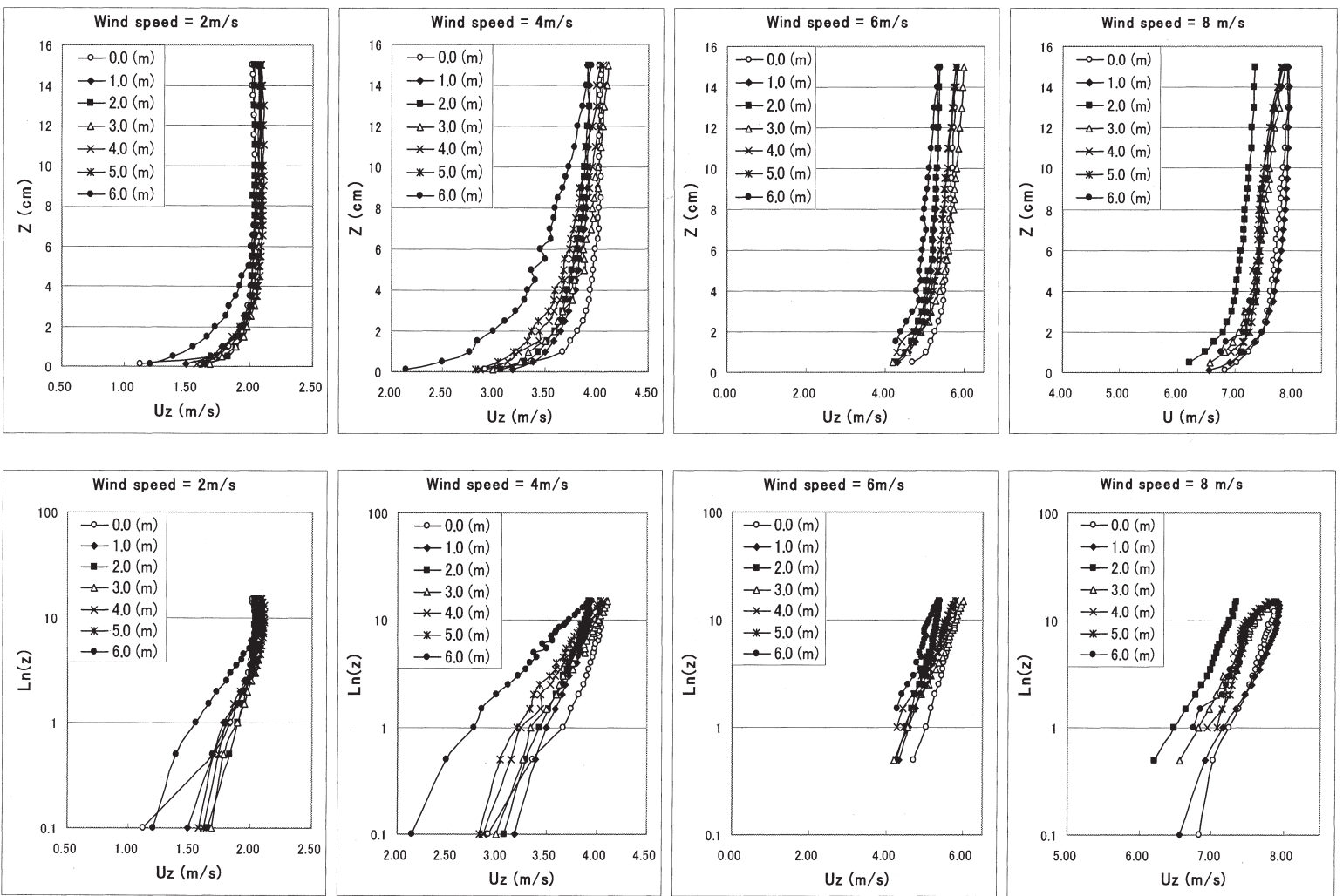

Fig. 5. Vertical velocity profiles and natural logarithm profiles of wind velocity $15 \mathrm{~cm}$ above the water surface in case without aquatic plant coverage on the water surface of the rectangular tank.
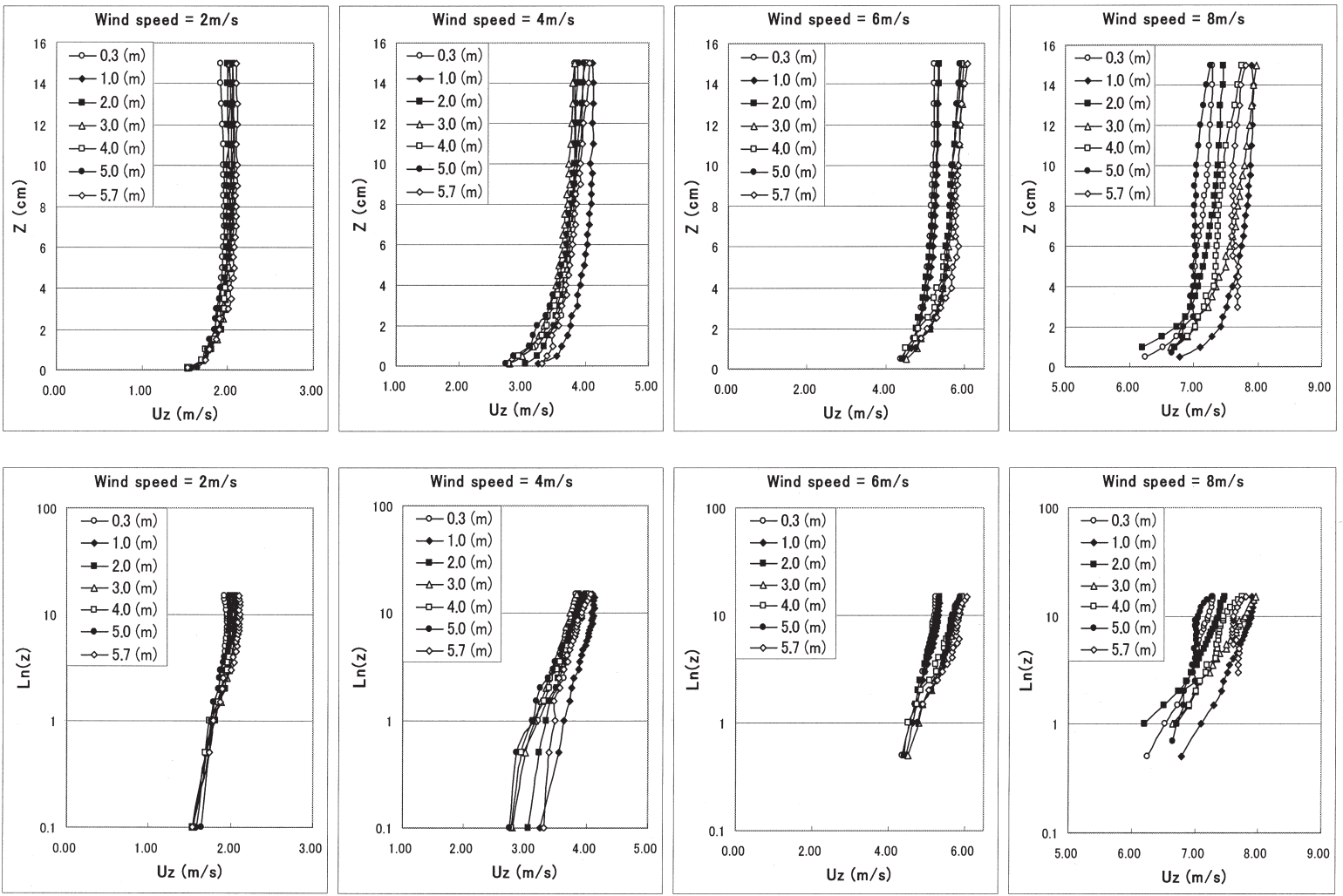

Fig. 6. Vertical velocity profiles and natural logarithm profiles of wind velocity $15 \mathrm{~cm}$ above the water surface in case with $10 \%$ aquatic plant coverage on the water surface of the rectangular tank. 

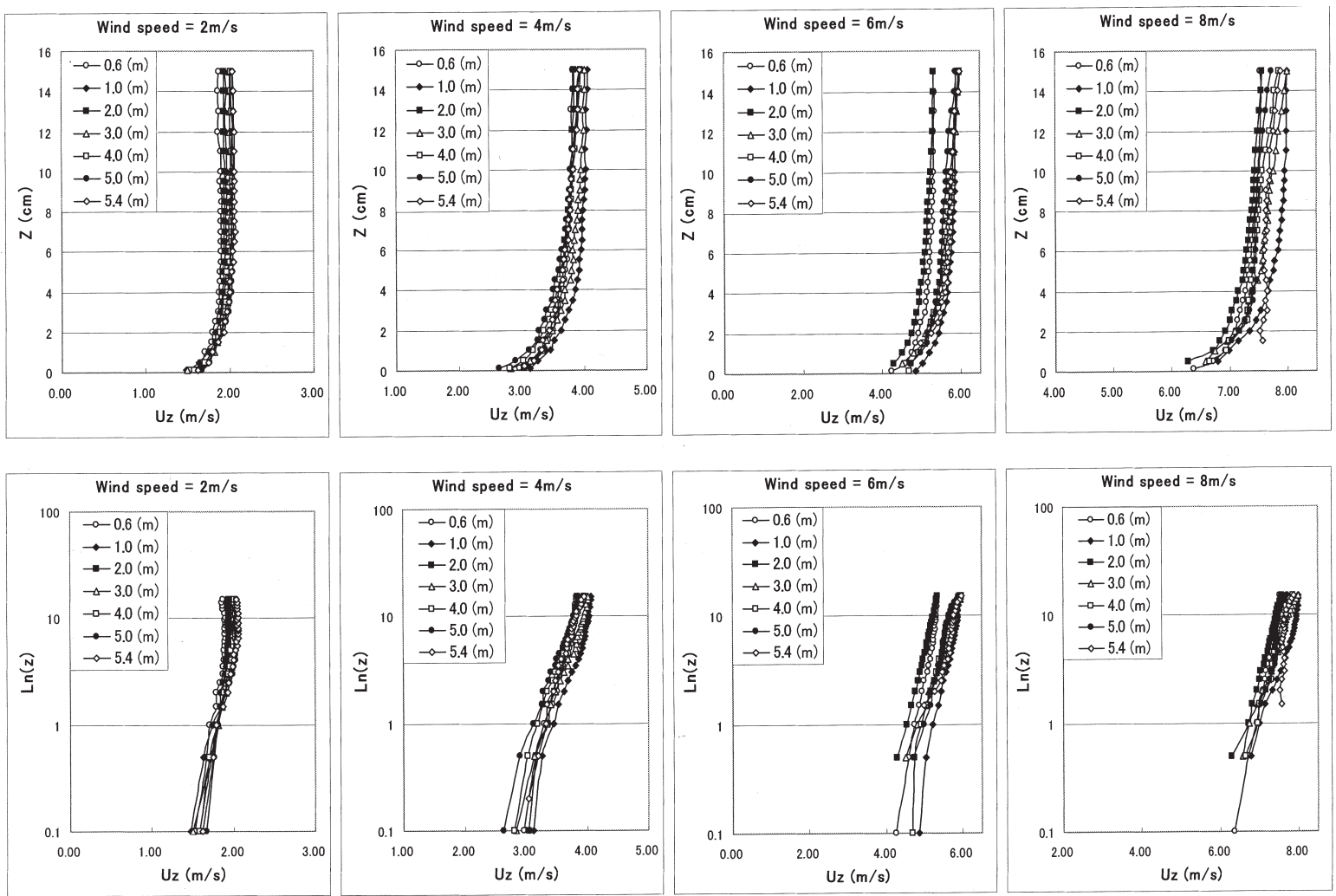

Fig. 7. Vertical velocity profiles and natural logarithm profiles of wind velocity $15 \mathrm{~cm}$ above the water surface in case with $20 \%$ aquatic plant coverage on the water surface of the rectangular tank.
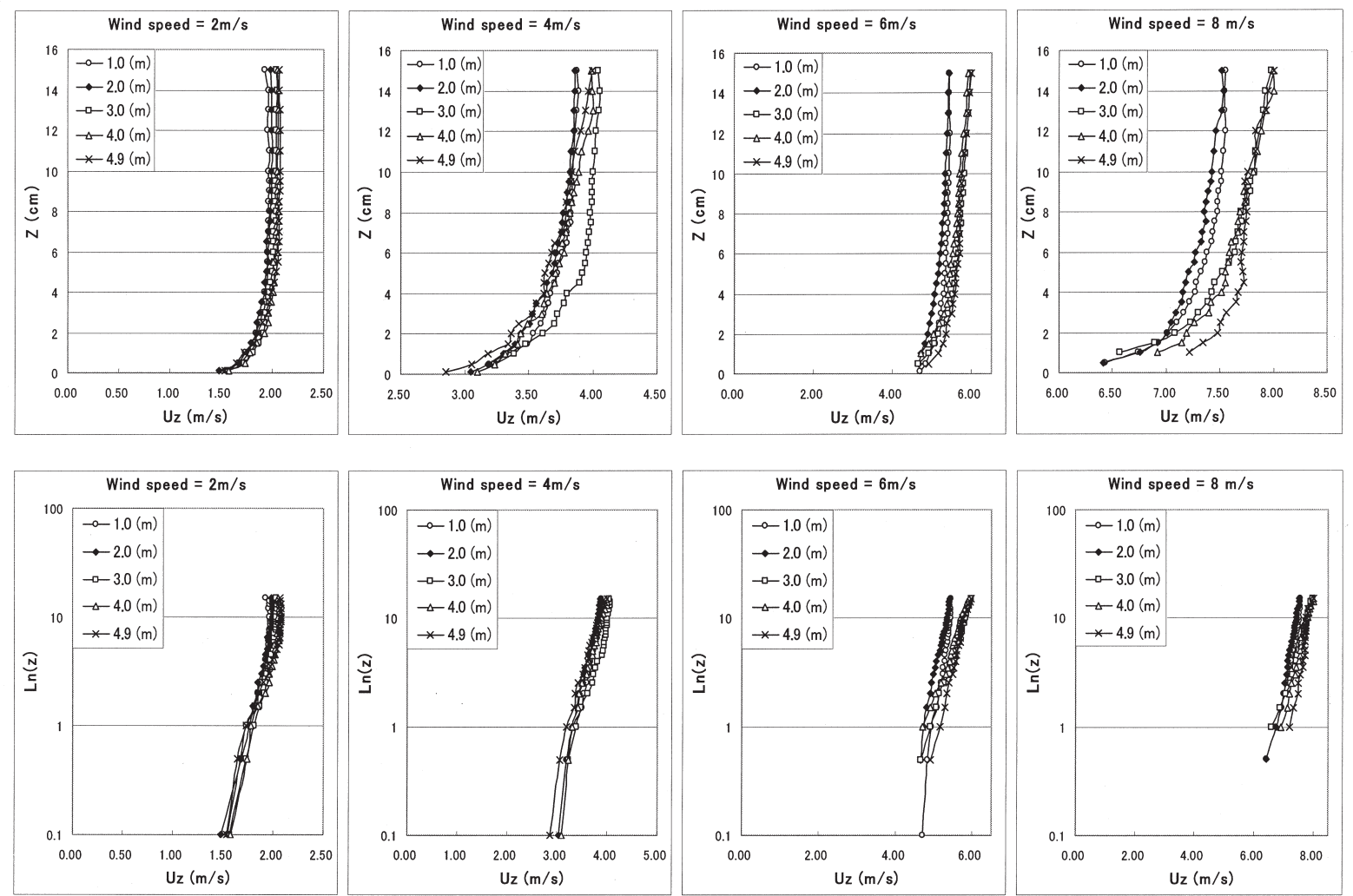

Fig. 8. Vertical velocity profiles and natural logarithm profiles of wind velocity $15 \mathrm{~cm}$ above the water surface in case with $35 \%$ aquatic plant coverage on the water surface of the rectangular tank. 

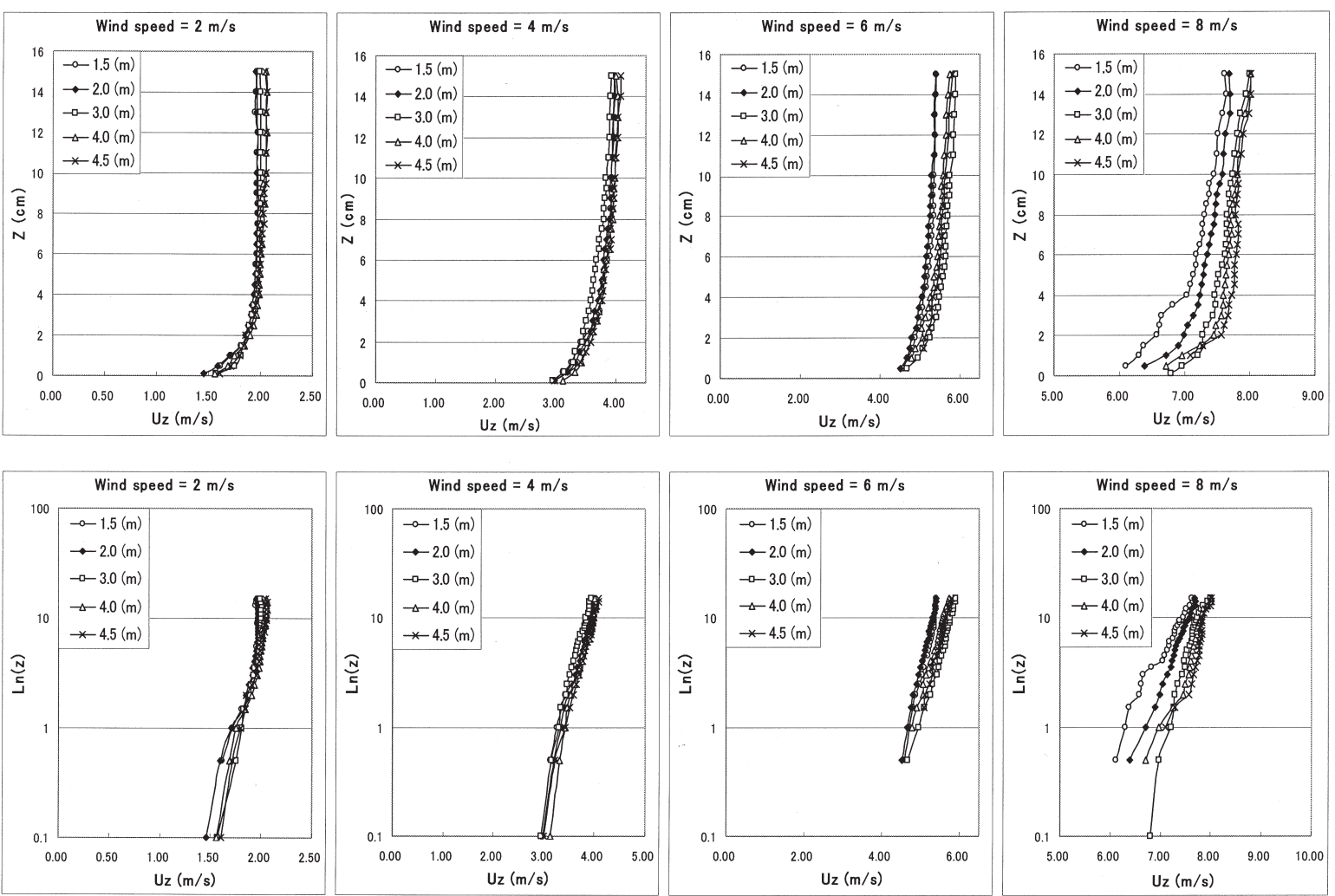

Fig. 9. Vertical velocity profiles and natural logarithm profiles of wind velocity $15 \mathrm{~cm}$ above the water surface in case with $50 \%$ aquatic plant coverage on the water surface of the rectangular tank.

the results of wind friction velocity, which are calculated from Equation (1), are shown in Fig. 10-Fig. 14 below.

It can be easily seen from Fig. 10 through Fig. 14 that in cases of average wind speed equal to $2 \mathrm{~m} / \mathrm{s}$ and $4 \mathrm{~m} / \mathrm{s}$, the variation of the wind friction velocity along the free water surface of the tank is not remarkable. In other words, in these cases, wind friction velocity is relatively homogeneous along the free water surface. However, in cases of average wind speed equal to $6 \mathrm{~m} / \mathrm{s}$ and $8 \mathrm{~m} / \mathrm{s}$, the variation of the wind friction velocity along the free water surface is remarkable. The wind friction velocity tends to increase from the beginning point (next to wind generating machine) to the ending

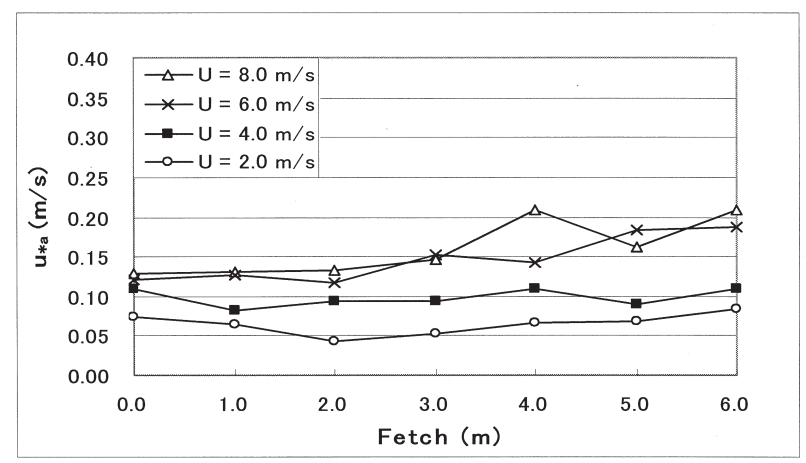

Fig. 10. The spatial variation of wind friction velocity on the water surface of the tank without aquatic plant coverage under different cases of average wind speed.

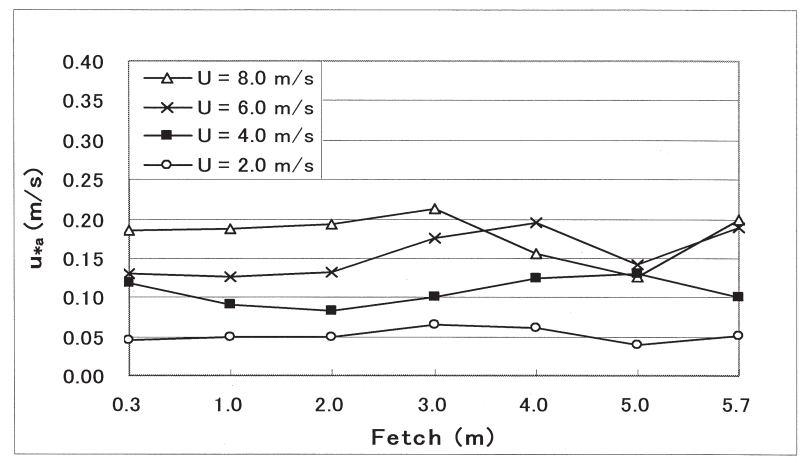

Fig. 11. The spatial variation of wind friction velocity on the water surface of the tank with $10 \%$ of aquatic plant coverage under different cases of average wind speed.

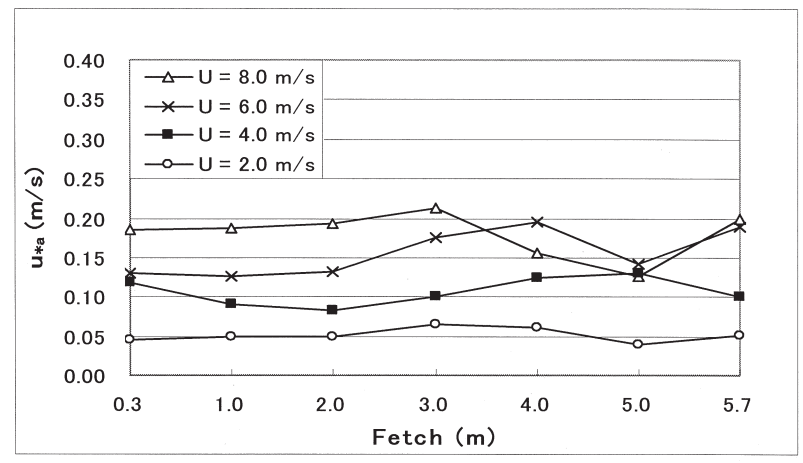

Fig. 12. The spatial variation of wind friction velocity on the water surface of the tank with $20 \%$ of aquatic plant coverage under different cases of average wind speed. 


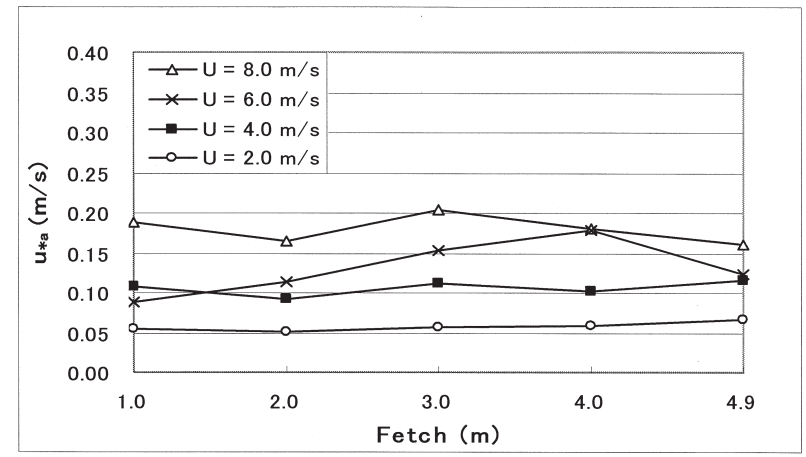

Fig. 13. The spatial variation of wind friction velocity on the water surface of the tank with $35 \%$ of aquatic plant coverage under different cases of average wind speed.

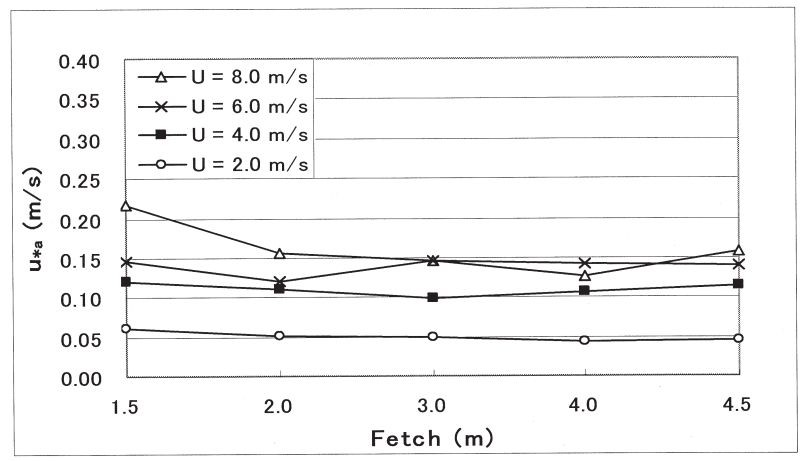

Fig. 14. The spatial variation of wind friction velocity on the water surface of the tank with $50 \%$ of aquatic plant coverage under different cases of average wind speed.

Table 1. The calculated results of wind friction velocity and water surface velocity

\begin{tabular}{|c|c|c|c|c|c|c|c|c|c|}
\hline \multirow{3}{*}{ Points } & \multicolumn{4}{|c|}{$\mathrm{u}_{\mathrm{w}_{\mathrm{a}}}(\mathrm{m} / \mathrm{s})$} & \multicolumn{4}{|c|}{$\mathrm{u}_{\mathrm{s}}(\mathrm{m} / \mathrm{s})$} & \multirow{3}{*}{ Note } \\
\hline & \multicolumn{4}{|c|}{$\mathrm{U}$} & \multicolumn{4}{|c|}{$\mathrm{U}$} & \\
\hline & $2 \mathrm{~m} / \mathrm{s}$ & $4 \mathrm{~m} / \mathrm{s}$ & $6 \mathrm{~m} / \mathrm{s}$ & $8 \mathrm{~m} / \mathrm{s}$ & $2 \mathrm{~m} / \mathrm{s}$ & $4 \mathrm{~m} / \mathrm{s}$ & $6 \mathrm{~m} / \mathrm{s}$ & $8 \mathrm{~m} / \mathrm{s}$ & \\
\hline $0.0 \mathrm{~m}$ & 0.075 & 0.108 & 0.121 & 0.129 & 0.081 & 0.117 & 0.131 & 0.139 & \multirow{9}{*}{ 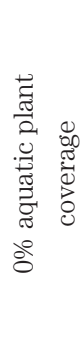 } \\
\hline $1.0 \mathrm{~m}$ & 0.064 & 0.083 & 0.126 & 0.131 & 0.069 & 0.089 & 0.136 & 0.142 & \\
\hline $2.0 \mathrm{~m}$ & 0.043 & 0.093 & 0.118 & 0.133 & 0.046 & 0.100 & 0.127 & 0.143 & \\
\hline $3.0 \mathrm{~m}$ & 0.053 & 0.094 & 0.152 & 0.146 & 0.057 & 0.101 & 0.164 & 0.157 & \\
\hline $4.0 \mathrm{~m}$ & 0.067 & 0.109 & 0.142 & 0.209 & 0.072 & 0.118 & 0.153 & 0.226 & \\
\hline $5.0 \mathrm{~m}$ & 0.068 & 0.090 & 0.183 & 0.162 & 0.073 & 0.097 & 0.197 & 0.174 & \\
\hline $6.0 \mathrm{~m}$ & 0.085 & 0.110 & 0.188 & 0.208 & 0.092 & 0.118 & 0.203 & 0.225 & \\
\hline Average & 0.065 & 0.098 & 0.147 & 0.160 & 0.070 & 0.106 & 0.159 & 0.172 & \\
\hline \multicolumn{5}{|c|}{$\mathrm{u}_{\mathrm{s}} / \mathrm{U}(\%)$} & 3.5 & 2.6 & 2.6 & 2.2 & \\
\hline $0.3 \mathrm{~m}$ & 0.046 & 0.118 & 0.131 & 0.186 & 0.049 & 0.127 & 0.141 & 0.201 & \multirow{9}{*}{ 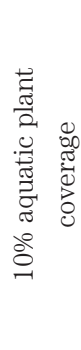 } \\
\hline $1.0 \mathrm{~m}$ & 0.049 & 0.090 & 0.127 & 0.188 & 0.053 & 0.097 & 0.137 & 0.203 & \\
\hline $2.0 \mathrm{~m}$ & 0.050 & 0.083 & 0.133 & 0.194 & 0.054 & 0.090 & 0.143 & 0.209 & \\
\hline $3.0 \mathrm{~m}$ & 0.065 & 0.101 & 0.176 & 0.213 & 0.070 & 0.109 & 0.190 & 0.230 & \\
\hline $4.0 \mathrm{~m}$ & 0.061 & 0.125 & 0.194 & 0.156 & 0.066 & 0.134 & 0.210 & 0.168 & \\
\hline $5.0 \mathrm{~m}$ & 0.040 & 0.131 & 0.141 & 0.126 & 0.043 & 0.141 & 0.152 & 0.136 & \\
\hline $5.7 \mathrm{~m}$ & 0.052 & 0.100 & 0.190 & 0.200 & 0.056 & 0.108 & 0.205 & 0.216 & \\
\hline Average & 0.052 & 0.107 & 0.156 & 0.180 & 0.056 & 0.115 & 0.168 & 0.195 & \\
\hline \multicolumn{5}{|c|}{$\mathrm{u}_{\mathrm{s}} / \mathrm{U}(\%)$} & 2.8 & 2.9 & 2.8 & 2.4 & \\
\hline $0.6 \mathrm{~m}$ & 0.048 & 0.086 & 0.100 & 0.108 & 0.052 & 0.093 & 0.108 & 0.117 & \multirow{9}{*}{ 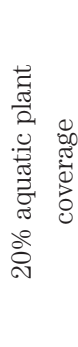 } \\
\hline $1.0 \mathrm{~m}$ & 0.052 & 0.108 & 0.113 & 0.186 & 0.056 & 0.117 & 0.122 & 0.201 & \\
\hline $2.0 \mathrm{~m}$ & 0.045 & 0.088 & 0.130 & 0.163 & 0.049 & 0.095 & 0.140 & 0.176 & \\
\hline $3.0 \mathrm{~m}$ & 0.056 & 0.109 & 0.174 & 0.188 & 0.060 & 0.118 & 0.188 & 0.203 & \\
\hline $4.0 \mathrm{~m}$ & 0.048 & 0.123 & 0.145 & 0.184 & 0.052 & 0.133 & 0.157 & 0.199 & \\
\hline $5.0 \mathrm{~m}$ & 0.051 & 0.124 & 0.140 & 0.179 & 0.055 & 0.134 & 0.151 & 0.194 & \\
\hline $5.4 \mathrm{~m}$ & 0.056 & 0.098 & 0.159 & 0.157 & 0.060 & 0.106 & 0.172 & 0.170 & \\
\hline Average & 0.051 & 0.105 & 0.137 & 0.167 & 0.055 & 0.114 & 0.148 & 0.180 & \\
\hline \multicolumn{5}{|c|}{$\mathrm{u}_{\mathrm{s}} / \mathrm{U}(\%)$} & 2.7 & 2.8 & 2.5 & 2.2 & \\
\hline $1.0 \mathrm{~m}$ & 0.055 & 0.107 & 0.089 & 0.189 & 0.059 & 0.115 & 0.096 & 0.204 & \multirow{7}{*}{ 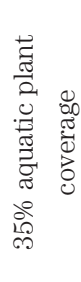 } \\
\hline $2.0 \mathrm{~m}$ & 0.052 & 0.093 & 0.114 & 0.164 & 0.056 & 0.100 & 0.123 & 0.177 & \\
\hline $3.0 \mathrm{~m}$ & 0.056 & 0.111 & 0.153 & 0.204 & 0.060 & 0.120 & 0.165 & 0.220 & \\
\hline $4.0 \mathrm{~m}$ & 0.059 & 0.102 & 0.179 & 0.180 & 0.064 & 0.110 & 0.193 & 0.194 & \\
\hline $4.9 \mathrm{~m}$ & 0.067 & 0.116 & 0.124 & 0.161 & 0.072 & 0.125 & 0.134 & 0.174 & \\
\hline Average & 0.058 & 0.106 & 0.132 & 0.179 & 0.062 & 0.114 & 0.142 & 0.194 & \\
\hline \multicolumn{5}{|c|}{$\mathrm{u}_{\mathrm{s}} \mathrm{s}(\mathrm{U}(\%)$} & 3.1 & 2.9 & 2.4 & 2.4 & \\
\hline $1.5 \mathrm{~m}$ & 0.061 & 0.121 & 0.146 & 0.217 & 0.066 & 0.131 & 0.158 & 0.234 & \multirow{7}{*}{ 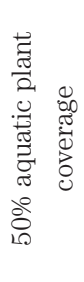 } \\
\hline $2.0 \mathrm{~m}$ & 0.052 & 0.111 & 0.121 & 0.155 & 0.056 & 0.120 & 0.131 & 0.167 & \\
\hline $3.0 \mathrm{~m}$ & 0.050 & 0.098 & 0.145 & 0.146 & 0.054 & 0.106 & 0.157 & 0.158 & \\
\hline $4.0 \mathrm{~m}$ & 0.044 & 0.107 & 0.141 & 0.127 & 0.048 & 0.116 & 0.152 & 0.137 & \\
\hline $4.5 \mathrm{~m}$ & 0.046 & 0.114 & 0.140 & 0.157 & 0.050 & 0.123 & 0.151 & 0.170 & \\
\hline Average & 0.051 & 0.110 & 0.139 & 0.160 & 0.055 & 0.119 & 0.150 & 0.173 & \\
\hline \multicolumn{5}{|c|}{$\mathrm{u}_{\mathrm{s}} \mathrm{dU}(\%)$} & 2.7 & 3.0 & 2.5 & 2.2 & \\
\hline \multicolumn{5}{|c|}{ Average u/U (\%) } & 3.0 & 2.8 & 2.6 & 2.3 & \\
\hline
\end{tabular}


point (outlet of the tank).

This can be explained that when wind speed is small ( $\leq 4.0 \mathrm{~m} / \mathrm{s}$ ), it is not strong enough to cause waves on the water surface. Therefore, the air cross-sections above the water surface are nearly constant. In other words, average wind speed on the water surface is relatively homogeneous along the tank. As a result, there is no much difference in the change of wind friction velocity along the tank. However, when wind speed is strong ( $\geq 6.0 \mathrm{~m} / \mathrm{s})$, it induces waves on the water surface. Due to the gradual development of waves from the beginning point to the ending point, the air cross-section above the water surface is partly narrowed around the ending point. It leads to the fact that the average wind speed around the ending point is somewhat higher than that at other positions of the tank. As a result, the wind friction velocity around the ending point is higher than that at the other positions as can be seen in Fig. 10-Fig. 14.

Table 1 shows the calculated results of the wind friction velocity $\left(u_{*_{\mathrm{a}}}\right)$ and the water surface velocity $\left(u_{\mathrm{s}}\right)$. The wind friction velocities have been shown and analyzed in Fig. 10-Fig. 14 above. From the wind friction velocity, the water surface velocity has been calculated by using the formula (3) above. By using the ratio of the water surface velocity $\left(u_{s}\right)$ to the average wind speed (U) $\left(u_{s} / U\right)$, we can see that when the average wind speed is equal to $2 \mathrm{~m} / \mathrm{s}$ (nearly no waves are generated), the water surface velocity is about $3 \%$ of the average wind speed. This result also agrees with previous researches (Cole and Buchak, 1995). When the average wind speed increases to $4 \mathrm{~m} / \mathrm{s}, 6 \mathrm{~m} / \mathrm{s}$ and $8 \mathrm{~m} / \mathrm{s}$, the water surface velocity decreases gradually to $2.8 \%, 2.6 \%$ and $2.3 \%$ of the average wind speed, respectively as indicated in Table 1 . The reason can be traced back to the effect of waves generated by strong winds.

\section{CONCLUSIONS}

From the results obtained above, some conclusions have been drawn as follows:

1. When average wind speed is small $(\leq 4.0 \mathrm{~m} / \mathrm{s})$, because the spatial variation of wind flow is nearly constant (it is not narrowed by water waves), the wind friction velocity along the water surface of the tank is relatively homogeneous. As a result, the water surface velocity is also homogeneous on the water surface.
2. When average wind speed is large $(\geq 6.0 \mathrm{~m} / \mathrm{s})$, the variation of the wind friction velocity along the water surface of the tank is remarkable. It tends to increase from the beginning point to the ending point of the tank because the wind flow is somewhat narrowed by high waves around the ending point of the tank.

3. It can be drawn that in reality, when wind flow is constant, the wind friction velocity is also homogeneous over the water surface of closed water bodies.

4. In the reality of application, when wind speed $\leq$ $4.0 \mathrm{~m} / \mathrm{s}$, the water surface velocity can be calculated as around $2.8 \%-3 \%$ of the average wind speed. The water surface velocity can be taken as about $2.6 \%-2.3 \%$ of the average wind speed when $6 \mathrm{~m} / \mathrm{s} \leq$ the average wind speed $\leq 8 \mathrm{~m} / \mathrm{s}$.

5. The conclusions drawn in this research is very useful for studying the wind-induced flow in setting boundary conditions on the free water surface of closed water bodies.

\section{ACKNOWLEDGEMENTS}

The authors would like to thank very much to Mr. Kunihiko Hamagami from Laboratory of Bioproduction and Environmental Information Sciences, Department of Bioproduction Environmental Sciences, Faculty of Agriculture, Kyushu University for his useful assistance during conducting the experiments of this research.

\section{REFERENCES}

Chapra, S. C 1997 Surface water-quality modeling. McGraw-Hill, New York, pp. 577-581

Cole, T. M and E. M. Buchak 1995 CE-QUAL-W2: A two-dimensional, laterally averaged, hydrodynamic and water quality model, Version 2.0: Users Manual, Instruction Report EL-95-1. U.S. Army Engineer Waterways Experiment Station, Vicksburg, MS, pp. 19-25

Fischer, H. B., E. J. List, R. C. Y. Koh, J. Imberger and N. H. Brooks 1979 Mixing in Inland and Coastal Waters. Academic Press, New York, pp. 161-163

Lap, B. Q. and K. Mori 2006 A two-dimensional model for water quality simulation in lakes and its application to Tabiishidani reservoir in Sasaguri-Fukuoka prefecture, Japan. J. Fac. Agr., Kyushu Univ., 51 (1): 19-27

Lap, B. Q. and K. Mori 2006 A two-dimensional simulation of flow field in lakes under wind acting on the water surface and the impact of aquatic plants on the flow patterns. J. Fac. Agr., Kyushu Univ., $\mathbf{5 1}$ (1): 13-18 